\title{
Time Trends of Head Injuries Over Multiple Seasons in Professional Male Football (Soccer)
}

\section{(ㄷ)(ㄱ) $($ ) $\Theta$}

\author{
Authors \\ Florian Beaudouin ${ }^{1}$, Karen aus der Fünten ${ }^{1}$, Tobias Tröß', Claus Reinsberger ${ }^{2}$, Tim Meyer ${ }^{1}$
}

Affiliations

1 Institute of Sports and Preventive Medicine, Saarland University, Saarbrücken, Germany

2 Institute of Sports Medicine, University of Paderborn, Paderborn, Germany

Key words

concussion, sport injury, epidemiology

received 20.09.2018

revised 26.10.2018

accepted 13.11.2018

Bibliography

DOI https://doi.org/10.1055/a-0808-2551

Published online: 2018

Sports Medicine International Open 2019; 3: E6-E11

(c) Georg Thieme Verlag KG Stuttgart · New York

ISSN 2367-1890

\section{Correspondence}

Mr. Florian Beaudouin

Institute of Sports and Preventive Medicine

Saarland University

Campus Building B 8-2, 66123 Saarbrücken

Germany

Tel.: + 49/681/302 70400, Fax: + 49/681/302 4296

florian.beaudouin@uni-saarland.de

\begin{abstract}
The present study aimed to investigate time trends of head injuries and their injury mechanisms since a rule change as monitoring may help to identify causes of head injuries and may advance head injury prevention efforts. Based on continuously recorded data from the German football magazine "kicker Sportmagazin ${ }^{\circledR ”}$ as well as other media sources, a database of head injuries in the $1^{\text {st }}$ German male Bundesliga was generated comprising 11 seasons (2006/07-2016/17). Injury mechanisms were analysed from video recordings. Injury incidence rates (IR) and $95 \%$ confidence intervals $(95 \% \mathrm{Cl}$ ) were calculated. Time trends were analysed via linear regression. Two hundred thirty-eight match head injuries occurred (IR $1.77 / 1000$ match hours, $95 \% \mathrm{Cl} 1.56-2.01)$. There were no significant seasonal changes, expressed as annual average yearon-year change, in IRs over the 11-year period for total head injuries ( $p=0.693)$, facial/head fractures $(p=0.455)$, lacerations/abrasions ( $p=0.162)$, and head contusions $(p=0.106)$. The annual average year-on-year increase for concussion was $6.4 \%(p=0.004)$. Five head injury mechanisms were identified. There were no seasonal changes in injury mechanisms over the study period. The concussion subcategory increased slightly over the seasons, which may either be a result of increasing match dynamics or raised awareness among team physicians and players.
\end{abstract}

\section{Introduction}

Prospective studies on head and neck injuries in professional male football (soccer) identified the unfair use of the upper extremity (particularly the elbow) as a significant cause of head and neck injuries $[1,15]$. As a consequence, the International Football Association Board (IFAB) changed the rules of the game in 2006 and deemed deliberate blows to the head from the elbow an instant red-card offence. The effect of this rule change has previously been investigated by comparing head injury data of the 2000/01-2005/06 seasons with data of the $2007 / 08-2012 / 13$ seasons [3]. Consequently, this preventative measure appeared to be efficient in reducing the number of head injuries ( $29 \%$ lower incidence rates after this rule change).
When considering the reported rise in the speed, technique, equipment, game play in general (e. g., tactics), increased number of matches in the seasonal schedule, time pressure, and general pressure on players [2, 7, 37], appropriate head injury monitoring is desirable. This approach may help to identify mechanisms and causes of head injuries and lead to advances in injury prevention strategies.

Currently, limited information is available on time trends of head injury rates over multiple seasons in professional male football $[11,33]$. This study intends to add beneficial information on the incidence of these injuries over a longitudinal period since the aforementioned IFAB rule change. This analysis includes the seasons after the rule change, but adds more seasons to expand the head injury database. Therefore, 
the present study (i) investigates the long-term seasonal variation of head injuries (and their diagnoses) sustained during match play after the rule change in the $2006 / 07$ season for 11 consecutive seasons and (ii) investigates the long-term seasonal variation of the most common mechanisms leading to head injuries in elite male football players. We hypothesized that head injuries and their mechanisms would present a continuous unaltered time trend over the years.

\section{Methods}

\section{Study design and injury assessment}

A standardized analysis of match head injuries in the first male German Bundesliga was completed encompassing the 2006/07 to 2016/17 seasons ( 11 full seasons; $2006 / 07$ to 2013/14 seasons retrospectively and $2014 / 15$ to $2016 / 17$ seasons prospectively). Since the 2006/07 season, intentional elbow-to-head blows have been punished with a red card. Data collection followed an a priori protocol and analysis plan. Data were mainly identified by a structured search in the "kicker Sportmagazin ${ }^{\circledR}$ " sports magazine (online edition). The magazine offers publicly available clinical information (diagnosis and time loss) and is published twice weekly with one journalist being responsible for one club and having contact with the press office of the club every day. The magazine contains injury reports and summaries of each match. The online versions also offered the opportunity for a free text search. Search terms were: concussions, traumatic brain injury, contusion, fracture, laceration, abrasion, face, head, neck, skull, cranium, zygomatic bone, mandible, maxilla, nose, and eye. Additionally, web pages (transfermarkt.de, ligainsider.de), social media of the players and teams (Twitter, Facebook and Instagram), team homepages and newsletters, TV sports channels (e. g., Sky Sports News), and local news (e. g., newspapers) were screened as a secondary data source to gain additional information on injuries by using the aforementioned search terms as well. Training head injuries are considerably lower compared to match head injuries and were not considered [33]. The injury mechanisms were assessed by video recordings. No research ethics board approval [21] was required for this study as all data were collected from public sources [10].

Data on diagnoses such as concussions/traumatic brain injuries (TBI), facial/head contusions, facial/head fractures, and facial/head lacerations/abrasions were collected. Injuries with an unclear description and unknown diagnosis were categorized as "other head injury". In case an injury encompassed more than one diagnosis, the most severe injury was recorded. For injuries with an unknown outcome (e. g., towards the end of the season), the mean time loss for the particular diagnosis in the present database was considered. The severity of injuries was based on the time loss according to the consensus statement in previous football injury research [16], which are categorised as slight (time loss 0 days), minimal (1-3 days), mild (4-7 days), moderate ( $8-28$ days), and severe ( $>28$ days).

\section{Incident assessment}

Categories for the head impact events during matches were [3]:

- Injury causation: contact with opponent or team mate, no contact with player, or unknown
- Injury mechanisms: head contact with head, hand, arm (forearm and upper arm), elbow, shoulder, pelvis, trunk, foot, knee, lower leg, thigh, ball, ground, advertising boards/ goalpost/corner flag

These criteria are in accordance with the analyses of injury mechanisms that have previously been published [15, 34, 35]. Video recordings were obtained from the official German Football League (“Die Liga - Fußballverband (DFL)") and wyscout ${ }^{\circledR}$. Wyscout is a video platform (payment required) that offers full matches of all European leagues. Additionally, different video sequences (actions, players, etc.) are readily available on the platform. Head injuries without video recordings are included in the analyses referring to total numbers and percentages.

\section{Match exposure}

Match exposure per team was calculated using the following calculation [16]: number of games $x$ number of players on the field (11 players) $x$ duration of the game in hours ( $1.5 \mathrm{~h}$ per match). The analysis included the 34 games in the regular Bundesliga season as well as additional cup games (e. g., DFB-Pokal and the UEFA Champions League). Extra time in knock-out games ( $2 \times 15 \mathrm{~min})$ was also included. Preparation and friendly games as well as national games were not analysed in this study.

\section{Statistical analysis}

All statistical analyses were performed using Microsoft Excel 2010 and Statistica 8 (Statsoft Europe GmbH, Hamburg, Germany). Injury incidence rates (IR) were calculated with the following formula [16]: incidence $=($ number of injuries $/$ hours of match exposure) $\times 1000$. For the incidence rates, $95 \%$ confidence intervals $(\mathrm{Cl})$ were calculated as follows [18]:

Lower $95 \% \mathrm{Cl}=$ Incidence $/ \mathrm{e}^{1.96 \times(\text { square root [1/number of incidents]) }}$

Upper $95 \% \mathrm{Cl}=$ Incidence $* \mathrm{e}^{1.96 \times(\text { square root [1/number of incidents]) }}$

Time trends, expressed as the average annual percentages of change, were analysed using a linear regression model with the logtransformed IR as the dependent variable $[12,19]$. The significance level was set at $\mathrm{p}<0.05$.

\section{Results}

\section{Exposure, time loss and injury incidence rates}

Total match exposure was $134,541 \mathrm{~h}$. Two hundred thirty-eight head injuries occurred corresponding to an IR of 1.77 (95\% Cl 1.562.01) per 1000 match hours. The IR for body contact-related head injuries was 1.50 (95\% Cl 1.31-1.72) per 1000 match hours. The head injury IRs per season across the 11-year study period are shown in $>$ Table 1.

The average time loss for total head injuries was $8 \pm 10$ days (median 4 , range $0-80$ days). Average time loss for concussion was $10 \pm 10$ days (median 6 , range $1-47$ days), for facial/head contusions $5 \pm 5$ days (median 3, range 1-21 days), for facial/head fractures $13 \pm 16$ days (median 7 , range $1-80$ days), and for facial/head 


\begin{tabular}{|c|c|c|c|c|c|c|c|c|c|c|c|c|c|}
\hline & 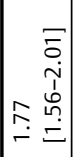 & 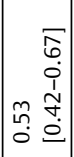 & 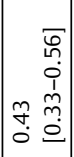 & 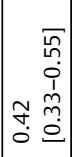 & $\mid$\begin{tabular}{r|r} 
& $\bar{\sigma}$ \\
0 \\
0 \\
0 \\
0 \\
0 \\
0 & 0 \\
0
\end{tabular} & 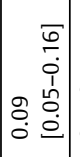 & \begin{tabular}{c|c} 
& \\
& \\
& \\
+1 & \\
$\infty$ &
\end{tabular} & $+\mid$ & & $\stackrel{2}{2}$ & $\bar{\sigma}$ & 呙 & \\
\hline & 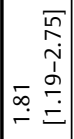 & 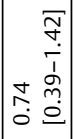 & 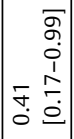 & 0 & 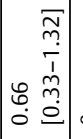 & 0 & 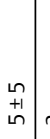 & $\mathrm{m}$ & $\begin{array}{l}\frac{n}{L} \\
\frac{1}{2}\end{array}$ & $F$ & 6 & in & 0 \\
\hline $\begin{array}{l}\frac{0}{2} \\
\frac{n}{2} \\
\stackrel{n}{N}\end{array}$ & 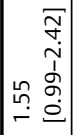 & 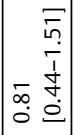 & 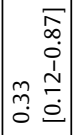 & 0 & 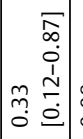 & $\mid$\begin{tabular}{r|}
0 \\
0 \\
0 \\
0 \\
0 \\
0 \\
0 \\
0 \\
0 \\
0
\end{tabular} & 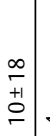 & & $\begin{array}{l}0 \\
0 \\
1 \\
1\end{array}$ & n & 6 & in & - \\
\hline $\begin{array}{l}\frac{n}{\sigma} \\
\frac{\sigma}{2} \\
\end{array}$ & 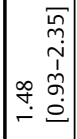 & 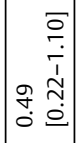 & 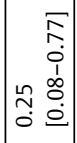 & 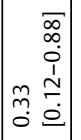 & 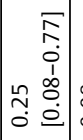 & 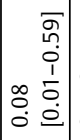 & $\begin{array}{c}0 \\
\stackrel{1}{+1} \\
\infty\end{array}$ & & 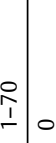 & . & $\mathrm{m}$ & ఠ & - \\
\hline$\frac{\vec{T}}{\bar{m}}$ & 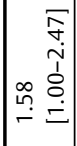 & 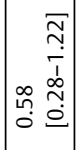 & 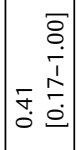 & 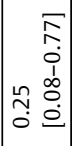 & 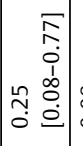 & 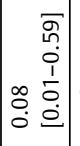 & $\begin{array}{l}m \\
+ \\
\forall\end{array}$ & & $\begin{array}{ll}I^{\prime} \\
\end{array}$ & $\simeq$ & in & & 0 \\
\hline $\begin{array}{l}\frac{m}{\bar{N}} \\
\stackrel{n}{\nu}\end{array}$ & 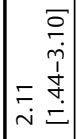 & 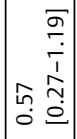 & 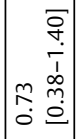 & 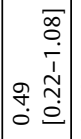 & 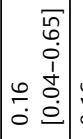 & 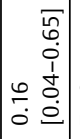 & $\begin{array}{l}\infty \\
\stackrel{\infty}{1} \\
\wedge\end{array}$ & & $\begin{array}{c}\infty \\
\stackrel{\infty}{\sim}\end{array}$ & r & \pm & $m$ & \\
\hline $\begin{array}{l}\frac{N}{\bar{v}} \\
\bar{\Sigma} \\
\end{array}$ & 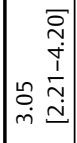 & 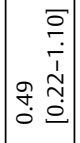 & 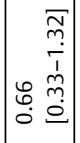 & 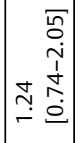 & 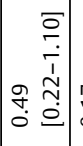 & \begin{tabular}{rr|} 
& 0 \\
& 0 \\
& 0 \\
1 & 0 \\
\hdashline & 0 \\
0 & 0
\end{tabular} & $\begin{array}{c}0 \\
+ \\
\infty \\
\infty\end{array}$, & & $\begin{array}{c}\stackrel{\infty}{I} \\
\stackrel{1}{*}\end{array}$ & $\infty$ & 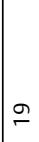 & $\infty$ & $\sim$ \\
\hline $\begin{array}{l}\bar{\sigma} \\
\overline{0} \\
\bar{N}\end{array}$ & 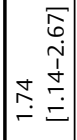 & 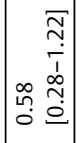 & 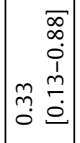 & 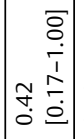 & 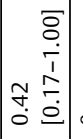 & 0 & $\begin{array}{l}n \\
⿱ \\
0 \\
0\end{array}$ & n $\mid \hat{\gamma}$ & $\begin{array}{c}\tilde{N} \\
\sim\end{array}$ & 0 & $m$ & $\sim$ & 0 \\
\hline 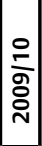 & 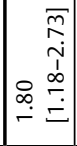 & 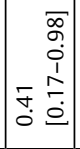 & 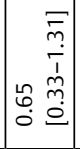 & 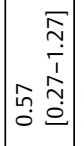 & 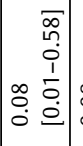 & $\left|\begin{array}{rr} & 0 \\
0 \\
0 \\
0 \\
0 \\
0 \\
0 \\
0 & 0 \\
0 & 0\end{array}\right|$ & & ๑ & $\begin{array}{l}\stackrel{\sim}{\sim} \\
\sim\end{array}$ & 0 & $\infty$ & $\infty$ & \\
\hline 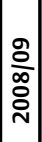 & 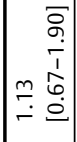 & 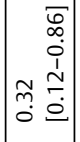 & 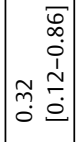 & 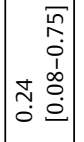 & 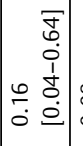 & $\mid \begin{array}{rr} & \pi \\
n \\
0 \\
0 \\
0 \\
0 \\
0 & 0 \\
0 & 0\end{array}$ & $\begin{array}{c}\circ \\
\stackrel{+}{+} \\
\stackrel{+1}{\sim} \\
\simeq\end{array}$ & $\sigma$ & $\begin{array}{c}\stackrel{\sim}{\sim} \\
\sim\end{array}$ & I & $\sigma$ & r & \\
\hline 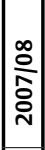 & 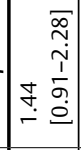 & 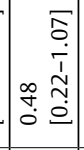 & 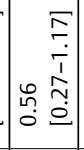 & 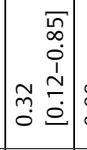 & 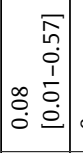 & & & \pm & $\begin{array}{c}L_{n} \\
\text { m. }\end{array}$ & N & 0 & & \\
\hline 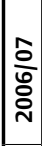 & 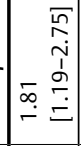 & 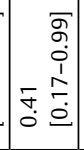 & 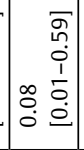 & 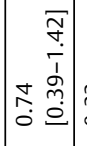 & 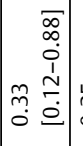 & 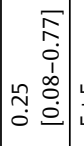 & $\begin{array}{l}+1 \\
n \\
n\end{array}$ & + & & in & & & \\
\hline & 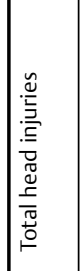 & 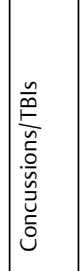 & 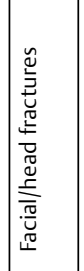 & 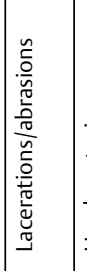 & 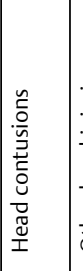 & 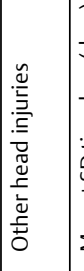 & 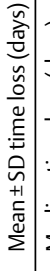 & 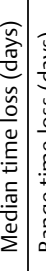 & 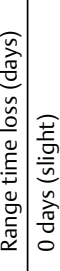 & 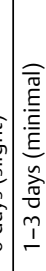 & 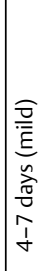 & 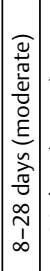 & \\
\hline
\end{tabular}

lacerations/abrasions $4 \pm 4$ days (median 4 , range 0 - 32 days). The time loss per season is displayed in $>$ Table 1 . The proportion of head injuries with an unknown outcome was $3 \%$. Of the 238 head injuries, $215(90 \%)$ could be analysed via video. The remaining 23 $(10 \%)$ could not be analysed in detail because either the video recordings were unavailable $(5 \%, \mathrm{n}=12)$ or, despite the video recordings being present, the injury mechanism was not apparent $(5 \%, n=11)$.

\section{Head injury epidemiology and time trends}

Time trends for all head injury types are shown in $>$ Fig. 1. No seasonal changes were found in the IRs for total head injuries $\left(R^{2}=0.018, b=0.010,95 \% \mathrm{Cl}-0.046\right.$ to $\left.0.066, p=0.693\right)$, facial/ head fractures $\left(R^{2}=0.064, b=0.047,95 \% \mathrm{Cl}-0.089\right.$ to 0.184 , $p=0.455)$, facial/head lacerations/abrasions $\left(R^{2}=0.205, b=-0.048\right.$ $95 \% \mathrm{Cl}-0.119$ to $0.023, \mathrm{p}=0.162$ ), or facial/head contusions $\left(R^{2}=0.263, b=0.107,95 \% \mathrm{Cl}-0.028\right.$ to $\left.0.242, p=0.106\right)$. The annual average year-on-year increase for concussion was $6.4 \%$ $\left(R^{2}=0.623, b=0.064,95 \% C l 0.026\right.$ to $\left.0.101, p=0.004\right)$.

\section{Head injury mechanisms and time trends}

The 5 predominant head injury mechanisms were head-againsthead contacts ( $38 \%$, IR $0.67 / 1000$ match hours, $95 \% \mathrm{Cl} 0.54-0.82$ ), elbow-to-head blows ( $16 \%$, IR 0.29/1000 match hours, $95 \% \mathrm{CI}$ $0.21-0.40)$, foot-to-head contacts ( $9 \%$, IR $0.16 / 1000$ match hours, $95 \% \mathrm{Cl} 0.11-0.25$ ), hand-to-head ( $5 \%$, IR $0.09 / 1000$ match hours, $95 \% \mathrm{Cl} 0.05-0.16)$, and knee-to-head contacts (5\%, IR 0.09/1000 match hours, $95 \% \mathrm{Cl} 0.05-0.16)$.

The time trends for the 5 most frequent head injury mechanisms are shown in $>$ Fig. 2 . Head-head $\left(R^{2}=0.056, b=0.028,95 \% \mathrm{Cl}\right.$ -0.058 to $0.113, p=0.483)$, elbow-head $\left(R^{2}=0.002, b=-0.003\right.$, $95 \% \mathrm{Cl}-0.046$ to $0.041, \mathrm{p}=0.894)$, foot-head $\left(R^{2}=0.009\right.$, $\mathrm{b}=-0.004,95 \% \mathrm{Cl}-0.036$ to $0.028, \mathrm{p}=0.0781)$, hand-head $\left(R^{2}=0.058, b=0.005,95 \% \mathrm{Cl}-0.010\right.$ to $\left.0.021, p=0.474\right)$, and knee-head $\left(R^{2}=0.024, b=-0.004,95 \% \mathrm{Cl}-0.022\right.$ to 0.014 , $\mathrm{p}=0.652)$ remained stable over 11 consecutive seasons.

\section{Discussion}

The main finding of this present study is that there were no significant seasonal changes for the IRs of total head injuries or for most of the subcategories such as facial/head fractures, facial/head lacerations/abrasions, and facial/head contusions over the 11-year period among male professional football players. The main head

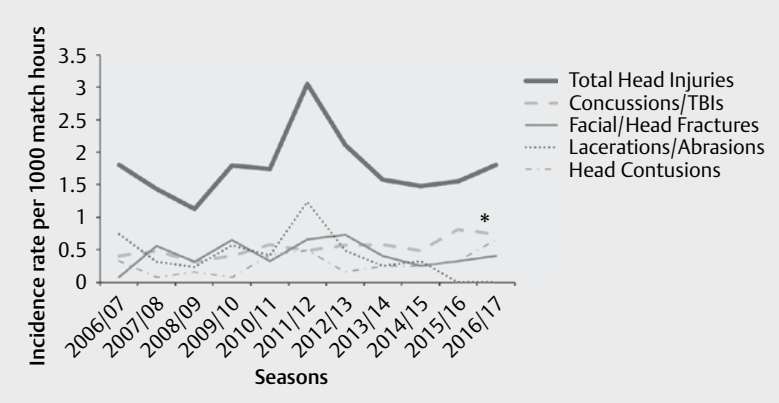

Fig. 1 Seasonal variation in head injury rates in 11 consecutive seasons. ${ }^{*} \mathrm{p}<0.05$. 


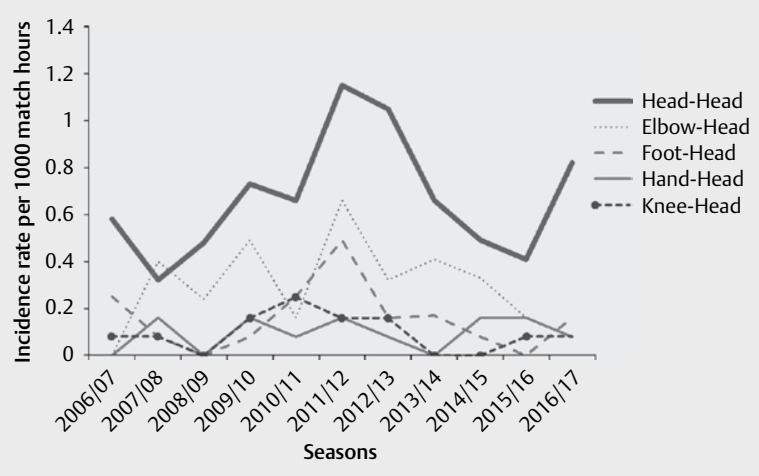

- Fig. 2 Seasonal variation in head injury mechanisms in 11 consecutive seasons.

injury mechanisms also showed no sign of change across the time period. However, an exception was the IR of concussion because it increased significantly year on year by $6.4 \%$.

The IRs of head injuries in this study were lower (approximately up to 20 times) compared to high-risk sports such as American football, ice hockey or rugby [8-10,17, 39], but still noteworthy because they can potentially lead to long-term sequelae such as postconcussion syndrome (PCS) or - if they occur repetitively chronic neurocognitive impairment (CNI), or even chronic traumatic encephalopathy (CTE) $[20,27,29]$. Although the present IRs ranged between 1.1 and 3.1 per 1000 match hours, it is likely that the true number of head injuries is somewhat higher due to the potential underreporting of injuries, because their signs and symptoms can rapidly change as well as rapidly disappear [29]. Head traumas/concussions are considered to be one of the most complex acute injuries in sports medicine to diagnose, assess and manage [29]. To date there is no perfect diagnostic test or marker for the immediate diagnosis of concussions [29]. The true number of unreported concussions in professional football is still unknown, but it appears that up to $30 \%$ of all concussions remain undiagnosed throughout different sports [30, 31, 38]. Undiagnosed concussions may be the result of being overlooked by non-medical professionals and/or even medical staff due to mild symptoms or even because of trivialized post-injury signs by the players themselves.

Compared to other football studies, the present IRs appear to be slightly higher. Head injury incidence rates of $0.74-1.70$ per 1000 match hours have been reported in recent years [ $1,6,33]$, whereas other studies found lower IRs as a result of adding training exposures to their analyses $[11,36]$. Injury rates in training are considerably low compared to match rates [12]. Nilsson et al. reported a 38-fold higher rate of head injuries during matches compared with training and even a 78-fold higher rate of concussions in matches [33]. The highest number of head injuries were reported during FIFA World Cup tournaments. Fuller et al. reported an incidence rate of head injuries of 12.5 per 1000 match hours with regards to 20 FIFA international tournaments [15]. Other tournament-related head injury data showed an almost similar incidence rate of 11.3 and 9.3 per 1000 match hours [23, 24]. It seems evident that it is difficult to compare head injury data from international tournaments with head injury data from regular league activity.
In the precursor study, the comparison of head injuries that were sustained before the rule change in the $2006 / 07$ season and data afterwards revealed a decrease of $29 \%$ [3]. The total IRs for the 11 -season period remained lower compared to the 2000/012005/06 seasons. Nevertheless, ongoing head injury monitoring remains essential in order to continue identifying the risk of sustaining head injuries and potential sequelae. Monitoring head injuries offers the opportunity to prevent their increase. Most head injury types showed no significant seasonal changes over 11 consecutive seasons, whereas the rate of concussions increased significantly by $6.4 \%$. This development is surprising. Potentially, the increasing awareness of head injuries in professional football over recent years may be a reasonable/valid explanation and responsible for the increase because more concussions may be reported $[20,27,29]$. Additionally, increasing match dynamics over the years could contribute to increasing numbers of concussions. Speed, techniques, equipment and game play in general (e. g., tactics) seem to experience a continuous evolution [7,37]. Especially physical and technical demands have increased substantially [2]. It is feasible and comprehensible that these evolutional trends may transfer to different (head) injuries as well.

Time loss and, consequently, breaks from football can differ regarding specific head injury types, but can also be dependent on appropriate treatment, recovery and injury complications. More comprehensive injuries (more than one diagnosis) might prolong the anticipated recovery time and thus the time loss and the return to play. The mean time loss for concussions was 10 days in this study, which is in accordance with a previous study in which the mean time loss was 10.5 days [33]. Return to play after sustaining a concussion was previously recommended after 7-10 days [29]. However, symptoms may persist even longer (e. g., PCS) [20, 25, 28]. The median time loss was 6 days suggesting that some concussed players returned to play in less than 1 week despite current consensus recommendations that emphasise a sufficient rest period to achieve full recovery [29].

Head-to-head contact was the main injury mechanism for head injuries in this study. It accounted for $38 \%$ of all head injuries and remained stable throughout the 11 -season time period. It has previously been considered to be the predominant injury mechanism with regard to the causation of head injuries [14, 33]. Similarly, the elbow-to-head mechanism did not change either over this time period. The rule change in 2006 was able to reduce elbow-to-head blows by about $23 \%$ when compared to seasons before the rule change [3]. A reduced number of elbow-to-head contacts was also described by Bjørneboe et al. after stricter interpretation of the rules over the duration of one season, supporting this decrease [6].

Prevention strategies and methods are required because head injuries bear the risk of long-term and potentially life-threatening consequences [22]. As most head injuries are the result of headto-head contact, prohibiting intentional elbow blows to the head may have had only a limited effect on the number of head injuries (which is possibly already "harvested" by the rule change). Instead, diminishing head-to-head contacts could be the target of future prevention strategies. Although, it is impossible to reduce or even eliminate any contact between players. A logical step in light of head injury prevention from a solely medical point of view the final solution would be banning these football-specific features that 
cause head-to-head contacts (e.g., header duels) from the game. But undoubtedly, this would change the "heart of football" because this is a fundamental part of football. Understanding potentially modifiable risk factors (e. g., fatigue, prior concussion, excessive post-injury exercise) would help to design, implement and evaluate appropriate prevention interventions to reduce the risk of head injuries [13,29]. Protective equipment such as head gear was previously discussed as a potential prevention tool, but currently there is no clear evidence of reduced frequencies or severity of head injuries in football [20,27, 32]. Potentially, specific strength training for the head-neck segment could be a reasonable method to reduce head injuries or at least their severity. Strong neck muscles may limit transmitted forces to the head and may stabilize the head during head impacts $[4,20]$. However, personal awareness of an imminent impact seems to be crucial because otherwise the player may be unable to adequately prepare the head-neck muscles for the upcoming impact forces [20,33].

\section{Methodological considerations and limitations}

Mixing retrospective data with prospective data inherits a large risk for bias because the prospective data are most likely recorded more precisely/complete and are therefore more accurate. However, as a prospective approach was not feasible for the 2006/07 to 2013/14 seasons (and given the fact that the strength of data collection in professional male football is the accuracy of time loss recording because full-time football players are seen daily by the medical staff and the fact that news including injuries is reported extensively by various media), the present analyses appear to be fairly complete. Furthermore, prospective data collection may increase head injury numbers as a result of increased registries, but this development was not apparent. Additionally, since the start of social media, the information about injuries and personal data of players has increased tremendously over the years, and despite this increased availability of information and increased interest in detailed players' data, the overall head injury incidence rate has not risen. Nevertheless, it remains possible that the increase in concussions may have been triggered by the prospective data collection in some seasons. Additionally, there may be some bias because injury reports by media sources have unarguably increased since 2006 . The present database does not include training head injuries because these injuries are considerably lower compared to match head injuries. The present data were not validated with medical records by each team's medical departments. The medical data were published by non-medical professionals and club staff, and thus their accuracy should be interpreted with caution. Despite this unknown validity in our database, this limitation most likely has no influence on our main hypothesis "time trends", because this limitation may be consistent over the years. Diagnoses obtained from medical records are the gold standard for research purposes $[1,6,15,33]$, but online sports databases have been previously used to gather information on injuries in professional football [26]. But even for gold standard research there is no guarantee of data integrity. Bjørnboe et al. found that medical staff reports underestimated the incidence of time-loss injuries by up to $20 \%$ [5].

Head injury mechanisms were investigated via video recordings. Ideally, the video recordings should provide various perspectives, slow motions and display high-resolution quality. These prerequi- sites were not always met, e. g., younger injuries compared to older injuries during the study period.

To evaluate time trends in head injury characteristics, we used a linear regression with log-transformed IRs as the dependent variable. This methodological approach was also conducted by Ekstrand et al. who analysed time trends in injury characteristics over 11 consecutive seasons with regard to muscle and ligament injuries in football [12]. However, time trends of facial/head lacerations/abrasions as well as the elbow-head, foot-head, hand-head, and kneehead injury mechanisms had to be calculated with their IR without log-transformation because they contained the value "zero". To date, it seems that no gold standard exists to evaluate time-trends in injury characteristics over multiple seasons [12].

\section{Conclusion}

The number, type and injury mechanisms of match head injuries among male professional football players remained stable with no seasonal variation over 11 consecutive seasons of the German Bundesliga since the rule change that penalized elbow blows to the head in 2006. However, the concussion subcategory increased slightly year on year over the seasons, which may either be a result of increasing match dynamics or raised awareness among team physicians. No seasonal trends were seen in head injury mechanisms. Further preventative strategies are required to decrease head injuries in professional male football. For instance, protective equipment could become promising. Furthermore, equally important as diminishing the number of head injuries is improving the accuracy in diagnosing and managing concussions. New protocols similar to NFL's "concussion safety protocol" could help to raise further awareness and recognition of concussions.

\section{Acknowledgements}

The authors wish to thank the "kicker Sportmagazin" magazine for granting access to their online editions and the German Federal Institute of Sports Science (BISp) for their funding.

\section{Conflict of Interest}

The authors declare that they have no conflict of interest.

\section{References}

[1] Andersen TE, Arnason A, Engebretsen L, Bahr R. Mechanisms of head injuries in elite football. $\mathrm{Br}$ J Sports Med 2004; 38: 690-696

[2] Barnes C, Archer DT, Hogg B, Bush M, Bradley PS. The evolution of physical and technical performance parameters in the English Premier League. Int J Sports Med 2014; 35: 1095-1100

[3] Beaudouin F, aus der Fünten K, Tröß T, Reinsberger C, Meyer T. Head injuries in professional male football (soccer) over 13 years $-29 \%$ lower incidence rates after of a rule change (red card). $\mathrm{Br}$ J Sports Med 2017 Jun 23. [Epub ahead of print]

[4] Becker S, Fröhlich M, Kelm J, Ludwig O. Change of muscle activity as well as kinematic and kinetic parameters during headers after core muscle fatigue. Sports 2017; 5: 1-7 
[5] Bjørneboe J, Flørenes TW, Bahr R, Andersen TE. Injury surveillance in male professional football; is medical staff reporting complete and accurate? Scand J Med Sci Sports 2011; 21: 713-720

[6] Bjørneboe J, Bahr R, Dvorak J, Andersen TE. Lower incidence of arm-to-head contact incidents with stricter interpretation of the laws of the game in Norwegian male professional football. Br J Sports Med 2013; 47: 508-514

[7] Bush M, Barnes C, Archer DT, Hogg B, Bradley PS. Evolution of match performance parameters for various playing positions in the English Premier League. Hum Mov Sci 2015; 39: 1-11

[8] Casson IR, Viano DC, Powell JW, Pellman EJ. Twelve years of National Football League concussion data. Sports Health 2010; 2: 471-483

[9] Cross M, Kemp S, Smith A, Trewartha G, Stokes K. Professional Rugby Union players have a $60 \%$ greater risk of time loss injury after concussion: A 2-season prospective study of clinical outcomes. $\mathrm{Br}$ J Sports Med 2016; 50: 926-931

[10] Donaldson L, Asbridge M, Cusimano MD. Bodychecking rules and concussion in elite hockey. PLoS One 2013; 8: e69122

[11] Ekstrand J, Hägglund M, Waldén M. Injury incidence and injury patterns in professional football: The UEFA injury study. $\mathrm{Br}$ J Sports Med 2011; 45: 553-558

[12] Ekstrand J, Hägglund M, Kristenson K, Magnusson H, Waldén M. Fewer ligament injuries but no preventive effect on muscle injuries and severe injuries: An 11-year follow-up of the UEFA Champions League injury study. Br J Sports Med 2013; 47: 732-737

[13] Finnoff JT, Jelsing E], Smith J. Biomarkers, genetics, and risk factors for concussion. PM R 2011; 3: S452-S459

[14] Fuller CW, Smith GL, Junge A, Dvorak J. The influence of tackle parameters on the propensity for injury in international football. Am J Sports Med 2004; 32: 43S-45S3S

[15] Fuller CW, Junge A, Dvorak J. A six year prospective study of the incidence and causes of head and neck injuries in international football. Br J Sports Med 2005; 39: i3-i9

[16] Fuller CW, Ekstrand J, Junge A, Andersen TE, Bahr R, Dvorak J, Hägglund M, McCrory P, Meeuwisse WH. Consensus statement on injury definitions and data collection procedures in studies of football (soccer) injuries. Br J Sports Med 2006; 40: 193-201

[17] Gissane C, Jennings D, Kerr K, White J. Injury rates in rugby league football: Impact of change in playing season. Am J Sports Med 2003; 31: 954-958

[18] Hägglund M, Walden M, Ekstrand J. Previous injury as a risk factor for injury in elite football: A prospective study over two consecutive seasons. Br J Sports Med 2006; 40: 767-772

[19] Hägglund M, Walden M, Ekstrand J. Injury recurrence is lower at the highest professional football level than at national and amateur levels: Does sports medicine and sports physiotherapy deliver? $\mathrm{Br}$ J Sports Med 2016; 50: 751-758

[20] Harmon KG, Drezner JA, Gammons M, Guskiewicz KM, Halstead M, Herring SA, Kutcher JS, Pana A, Putukian M, Roberts WO. American Medical Society for Sports Medicine position statement: Concussion in sport. Br J Sports Med 2013; 47: 15-26

[21] Harriss D], Macsween A, Atkinson G. Standards for ethics in sport and exercise science research: 2018 Update. Int J Sports Med 2017; 38: $1126-1131$

[22] Jordan BD. Chronic traumatic encephalopathy and other long-term sequelae. Continuum (Minneap Minn) 2014; 20: 1588-1604
[23] Junge A, Dvorak J. Injury surveillance in the World Football Tournaments 1998-2012. Br J Sports Med 2013; 47: 782-788

[24] Junge A, Dvorak J. Football injuries during the 2014 FIFA World Cup. Br J Sports Med 2015; 49: 599-602

[25] King NS. A systematic review of age and gender factors in prolonged post-concussion symptoms after mild head injury. Brain Inj 2014; 28: 1639-1645

[26] Leventer L, Eek F, Hofstetter S, Lames M. Injury patterns among elite football players: A media-based analysis over 6 seasons with emphasis on playing position. Int J Sports Med 2016; 37: 898-908

[27] Levy ML, Kasabeh AS, Baird LC, Amene C, Skeen J, Marshall L. Concussions in soccer: A current understanding. World Neurosurg 2012; 78: 535-544

[28] McCrea M, Guskiewicz K, Randolph C, Barr WB, Hammeke TA, Marshall SW, Powell MR, Woo Ahn K, Wang Y, Kelly JP. Incidence, clinical course, and predictors of prolonged recovery time following sport-related concussion in high school and college athletes. J Int Neuropsychol Soc 2013; 19: 22-33

[29] McCrory P, Meeuwisse WH, Dvorak ], Aubry M, Bailes ], Broglio S, Cantu RC, Cassidy D, Echemendia RJ, Castellani RJ, Davis GA, Ellenbogen R, Emery C, Engebretsen L, Feddermann-Demont N, Giza CC, Guskiewicz KM, Herring S, Iverson GL, Johnston KM, Kissick J, Kutcher J, Leddy J], Maddocks D, Makdissi M, Manley GT, McCrea M, Meehan WP, Nagahiro S, Patricios J, Putukian M, Schneider KJ, Sills A, Tator $\mathrm{CH}$, Turner M, Vos PE. Consensus statement on concussion in sport - the $5^{\text {th }}$ International Conference on Concussion in Sport held in Berlin, October 2016. Br J Sports Med 2017; 51: 838-847

[30] Meehan WP 3rd, Mannis RC, O’Brien RJ, Collins MW. The prevalence of undiagnosed concussions in athletes. Clin I Sport Med 2013; 23: 339-342

[31] Meier TB, Brummel B], Singh R, Nerio C], Polanski DW, Bellgowan PS. The underreporting of self-reported symptoms following sports-related concussion. J Sci Med Sports 2015; 18: 507-511

[32] Niedfeldt MW. Head injuries, heading and the use of headgear in soccer. Curr Sports Med Rep 2011; 10: 324-329

[33] Nilsson M, Hägglund M, Ekstrand J, Waldén $M$. Head and neck injuries in professional soccer. Clin J Sport Med 2013; 23: 255-260

[34] Tscholl P, O’Riordan D, Fuller CW, Dvorak J, Junge A. Tackle mechanisms and match characteristics in women's elite football tournaments. Br J Sports Med 2007; 41: i15-i19

[35] Tscholl P, O'Riordan D, Fuller CW, Dvorak J, Gutzwiller F, Junge A. Causation of injuries in female football players in top-level tournaments. Br J Sports Med 2007; 41: i8-i14

[36] Waldén M, Hägglund M, Ekstrand J. UEFA Champions League study: A prospective study of injuries in professional football during the 2001-2002 season. Br J Sports Med 2005; 39: 542-546

[37] Wallace JL, Norton KI. Evolution of World Cup soccer final games 1966-2010: Game structure, speed and play patterns. J Sci Med Sport 2014; 17: 223-228

[38] Williamson IJS, Goodman D. Converging evidence for the underreporting of concussions in youth ice hockey. $\mathrm{Br}$ J Sports Med 2006; 40: $128-132$

[39] Zuckerman SL, Kerr ZY, Yengo-Kahn A, Wassermann E, Covassin T, Solomon GS. Epidemiology of sports-related concussion in NCAA athletes from 2009-2010 to 2013-2014: Incidence, recurrence, and mechanisms. Am J Sports Med 2015; 43: 2654-2662 